\title{
CROWDSOURCED CONSTITUTION COMO MEIO DE EXERCÍCIO DA DEMOCRACIA DIRETA $^{1}$
}

CROWDSOURCED CONSTITUTION AS A MEDIA FOR THE EXERCISE OF DIRECT

DEMOCRACY

Gustavo Henrique Silva ARANTES ${ }^{2}$

ISSUE DOI: $10.21207 / 2675-0104.2019 .945$

\begin{abstract}
RESUMO
O objetivo desse artigo científico é demonstrar a inovação da democracia participativa, por meio da inserção do Crowdsourced Constitutuion na comunidade jurídica, o qual possibilita o novo meio alternativo de consulta à população, instrumento este que habilita a sociedade virtual decidir sobre os mais e variados temas que vem a ter relevância dentro da sociedade, por meio do "plebiscito virtual". Tal tema será embasado no procedimento adotado pela Islândia.

Palavras-Chaves: Democracia Direta. Plebiscito Virtual. Meio alternativo de consulta à população.
\end{abstract}

\section{ABSTRACT}

The objective of this scientific article is to demonstrate the innovation of participatory democracy by inserting the Crowdsourced Constitutuion into the legal community, which enables the new alternative means of consultation with the population, which enables the virtual society to decide on the most varied subjects. that comes to have relevance within society, through the "virtual referendum". This theme will be based on the procedure adopted by Iceland.

Keywords: Direct Democracy. Virtual Plebiscite. Alternative means of consulting the population.

\footnotetext{
${ }^{1} \mathrm{O}$ presente artigo sintetiza a monografia de conclusão da pesquisa, realizada para o Programa Interno de Bolsas de Iniciação Científica (PIBIC 2018-2019) da Faculdade de Direito de Franca (FDF), Franca/SP.

${ }^{2}$ Discente da Faculdade de Direito de Franca (FDF), Franca/SP. Bolsista do Programa Interno de Bolsas de Iniciação Científica (PIBIC 2018-2019).
} 


\section{INTRODUÇÃO}

A tese principal deste artigo é a ideia de exercício de democracia participativa, que poderá ser exercida pelos meios tecnológicos sem gerar custos exorbitantes ao Estado, assim sendo poderá realizar consulta à população com mais frequência.

O trabalho irá demonstrar o surgimento da democracia, as formas de exercê-las e, principalmente, os tipos que existem no panorama jurídico e político.

Junto a isso, o presente autor vai discorrer sobre o Crowdsourced Constitution ocorrido na Islândia, fato este, que pode ser inserido de forma positiva no ambiente democrático, não somente nas elaborações de normas constitucionais, como para decidir questões polêmicas que estão à baila da sociedade.

Por fim, a pesquisa vai desmiuçar grandes autores a que dissertaram ao longo da História sobre a democracia, principalmente a importância dela, usando dos variados momentos históricos, como na idade antiga, local de seu nascimento, e, sua desenvoltura no continente americano usando do respaldo da sabia deliberação de Alexis de Tocqueville.

\section{DA DEFINIÇÃO DE CROWDSOURCED}

\subsection{DO CROWDSOURCED}

O Crowdsourced tem como supedâneo a participação de vários entes da sociedade na elaboração de uma norma. $\mathrm{O}$ mencionado instituto tem origem americana, ao passo que a etimologia da palavra "Crowdsourced", segundo o dicionário Michaelis "é um modelo de criação e/ou produção, que conta com a mão-de-obra e conhecimento coletivos, para desenvolver soluções e criar produtos". 3

Posto isto, nota-se, que o aludido instituo não se aplica tão somente no Direito, também pode ser usado em outras áreas do conhecimento, como por exemplo numa criação de determinado projeto dentro de uma empresa.

\footnotetext{
${ }^{3}$ MICHAELIS,Henriette. Dicionário Michaelis em Inglês. 22. ed. São Paulo: Melhoramentos, 2015.
} 
Por outro lado, o Crowdsourced teve sua relevância no âmbito do direito, pois como será visto adiante, a Islândia foi promissora na aplicação deste instituto.

\subsection{A EXPERIÊNCIA DA ISLÂNDIA}

A Islândia sofreu em 2008 uma grave crise financeira acarretando na necessidade de se fazer uma reforma constitucional, com intenção de corroborar esse ato, a população saiu às ruas fazendo movimentos sociais. O qual se mais se destacou sendo o Kitchenware Revolution (similar ao "panelaço" ocorrido no Brasil), demonstrando o total descontento dos islandeses. Em 27 de novembro de 2010, ocorreu a eleição para a assembleia constituinte elegendo-se 25 pessoas, sem vinculação partidária, com o intuito de elaborar uma nova constituição.

$\mathrm{O}$ autor Pedro Lenza foi um dos poucos autores brasileiros a dissertar sobre esse tema, e no seu relato ele assim o menciona: "As discussões foram transmitidas ao vivo e com a possibilidade de participação popular por meio das redes sociais, como Twitter, Facebook, Youtube e Flickr. Mais de 3600 sugestões foram postadas na página oficial no Facebook. Em 29 de julho de 2011, o documento (draft) foi encaminhado O Parlamento.

Antes da deliberação parlamentar, havia a previsão de análise do documento por referendo popular, sem caráter vinculativo e que foi realizado em 20 de outubro de 2012, contudo com a participação de $49 \%$ dos eleitores e, desses, $73 \%$ reconhecendo o draft como a nova Constituição do país.

Infelizmente, o Parlamento não aprovou o documento, seja por sua troca durante o processo de elaboração do draft (perda de apoio político), seja pela presença, em sua composição, de uma ala extremamente conservadora.

A experiência islandesa, contudo, e apesar da particular realidade de ter mais de $95 \%$ de sua pequena população de cerca de 320.000 habitantes conectada à internet (a maior porcentagem no mundo), revela uma nova forma de democracia e de participação popular por meio das redes sociais (internet) e que, sem dúvida, passa a servir de modelo para o futuro. 


\begin{abstract}
Estamos diante daquilo que vem sendo denominado crowdsourced constitution e que implementa pela participação popular por meio da internet (crowdsourcing), em um processo constituinte bastante interessante de terceirização para a multidão. Sem dúvida, as novas formas de democracia utilizando as ferramentas da tecnologia podem ajudar nesse modelo de verdadeira Constituição colaborativa. ${ }^{4}$
\end{abstract}

Nota-se que o modelo de participação da população, ocorrido na Islândia, é uma definição clara de democracia direta, instituto esse que foi praticamente inativo por um grande período histórico, e agora com a evolução da internet, pode ser cotado como opção a se reconsiderar. E também é importante ressaltar que todo o procedimento realizado pelos islandeses traz para o estudo do direito mais uma nova definição de constituição, denominada constituição colaborativa.

\title{
2.3 CONCEITO DE CROWDSOURCED NO ÂMBITO DO DIREITO
}

A palavra crowdsourced tem origem inglesa, cuja sua tradução para o vernáculo brasileiro, dá-se o significado de contribuição colaborativa ou colaboração coletiva, esse termo foi definido em 2005 pelo dicionário Merriam-Webster como o processo obtenção de serviços, ideias ou conteúdo mediante a solicitação de contribuições de um grande grupo de pessoas e, especialmente, de uma comunidade online. ${ }^{5}$

O Crowdsourced Constitution, que deu origem a constituição colaborativa, pode ser enquadrado no processo constituinte da Islândia, pois as normas, as ideias e os comentários foram discutidos por uma comunidade online. Mais necessariamente na página do Conselho, feita unicamente para esse fim, constatando-se 323 propostas formais, das quais a assembleia constituinte discutiu mais de 3600 comentários escritos que foram publicados pelos usuários.

A maioria das propostas e comentários recebidos se mostraram úteis de uma forma ou de outra, não apenas o que foi dito, mas também as coisas não ditas. Se ninguém se opusesse aos artigos provisórios postados no site, talvez não estivesse no caminho certo.

\footnotetext{
${ }^{4}$ LENZA, Pedro. Direito constitucional esquematizado. 21. ed. São Paulo: Saraiva. 2017, p. 89-90.

${ }_{5}^{5}$ Definition of crowdsourcing. Merriam-Webster, 2019. Disponível em: https://www.merriamwebster.com/dictionary/crowdsourcing. Acesso em 17 fev. 2019.
} 
Cinquenta entrevistas com membros do conselho e outros interessados foram postadas na plataforma Youtube, e até o final de 2011, foram vistas por mais de 5000 vezes. O site contém muitas informações sobre o trabalho da constituinte e material relacionado, incluindo a cobertura da imprensa nacional e no exterior. Embora infelizmente tudo isso em islandês, exceto para cobertura externa. ${ }^{6}$

Portanto, o Crowdsourced é um instituto inovador para a população no que tange o exercício da democracia direta, como foi enaltecido anteriormente no país referido, pois a ideia principal desse instituto é colaboração de determinado grupo indefinido (que no caso relatado esses seriam os usuários da internet) para a obtenção de um resultado que deveria somente ser alcançado por pessoas que detém o poder para tanto.

\subsection{DAS PRELIMINARES DA APLICAÇÃO DO CROWDSOURCED}

Nesta senda, o início do processo constituinte na Islândia teve um preparo, o qual pautou e pesquisas na sociedade islandesa, e, ficou claro que população em linhas gerais queria um grande ruptura no sistema, com isso ficou evidente que era imprescindível a participação da sociedade na construção da carta magna, do contrário vejamos;

Ficou claro desde o início que as pessoas queriam mudanças. De acordo com as conclusões da Assembleia Nacional convocada no mês anterior, as respostas que os candidatos da Assembleia Constitucional deram à mídia antes de novembro de 2010 as eleições refletiram um amplo consenso de que são necessárias mudanças substanciais na constituição.

Com base nas respostas dadas por 23 dos 25 candidatos que foram eleitos afirmaram que eram favoráveis à mudança da constituição, 22 estavam em a favor da igualdade de direitos de voto em todo o país, 22 eram a favor da propriedade pública recursos naturais, 21 eram favoráveis a referendos nacionais mais frequentes, 20 favoreciam fortalecendo o direito do público à informação, 20 se opuseram ao direito dos ministros para manter seus assentos no parlamento, eram a favor da preservação do direito do presidente de submeter leis a um referendo nacional, 18 se opuseram a permitir que os ministros nomeassem funcionários por conta

\footnotetext{
${ }^{6}$ GYLFASON, Thorvaldur. From colapse to Constittution: the case of Iceland. Traduzido pelo presente autor. $1^{\circ}$ ed. Reykjavík. GlobalGovernanceandEconomicDynamism. p. 379-417.
} 
própria e 16 eram a favor de permitir que os eleitores votassem em candidatos e não apenas para as chapas do partido. Por último, mas não menos importante, todos os 23 eram contra a permissão de ministro da justiça (agora ministro do interior) para nomear juízes por conta própria. Para entender os 23 dos 23, ajuda saber que ao longo da história da república uma grande maioria das nomeações judiciais foi feita por ministros pertencentes à dois partidos políticos dominantes há muito tempo, o Partido da Independência e o Partido Progressista. Segundo pesquisas de opinião, a confiança do público nos tribunais tem sido quase tão baixa quanto confiança do público no parlamento. O problema persiste. Em 2011, de acordo com Market e Media Research, um dos principais pesquisadores, apenas um em cada três expressou grande confiança no sistema judicial em comparação com um em cada dez que expressou grande confiança no parlamento.

Em suma, os representantes eleitos queriam mais democracia, mais respeito pelos direitos humanos, mais freios e contrapesos, mais transparência e menos corrupção. Pesquisas de opinião sugeriram que o amplo consenso entre os representantes eleitos, bem como entre os 523 candidatos refletiu não apenas os sentimentos da Assembleia Nacional participaram 1.000 cidadãos selecionados aleatoriamente, mas refletiram também a opinião pública. Por exemplo, em vista da hipótese de Ackerman (2004) de que, através do envolvimento popular, as pessoas têm uma visão mais positiva de seus governos e instituições governamentais, seria empiricamente se o os delegados na Assembleia Nacional continuam tão desconfiados do parlamento quanto a população em geral.

$\mathrm{O}$ amplo consenso entre os representantes sobre a necessidade de comprovar, ou melhor, recuperar, os direitos de propriedade das pessoas sobre seus recursos naturais estão de acordo a opinião pública pesquisas que por muitos anos mostraram consistentemente cerca de $70 \%$ do como oposta à natureza discriminatória do sistema de gestão das pescas que virou um pequeno de proprietários de barcos para bilionários e grandes corretores políticos. O Nacional ecoou esse sentimento popular. O Conselho Constitucional considerou-se obrigado por lei, levar em as resoluções da Assembleia Nacional. Portanto, ninguém precisava ser surpreendido quando o Conselho Constitucional aprovou e entregou ao parlamento projeto de lei constitucional que, se ratificado em referendo nacional e aprovado por dois sucessivos parlamentos, implicará uma grande reforma na constituição da Islândia. 
No início do trabalho do Conselho Constitucional, ficou claro que a maioria de seus membros queria começar com uma lousa limpa, escrever uma nova constituição a partir do zero, em vez de revisar o existente. Mesmo assim, o conselho chegou a um consenso, aprovando o projeto após quatro meses de trabalho com 25 votos contra zero, uma façanha notável, principalmente pelo fato de que as reformas propostas são bastante abrangentes e radicais de várias maneiras. O projeto enfatiza freios e contrapesos mais fortes entre os três ramos do governo, bem como entre poder e responsabilidade. Salienta transparência, justiça, proteção do meio ambiente, e exploração eficiente e justa, além da propriedade nacional dos recursos naturais do país. O objetivo é acabar com a corrupção e o sigilo, mas deixa as duas palavras não ditas. No mesmo tempo, o projeto promete continuidade e estabilidade, preservando e fortalecendo a forma do governo parlamentar estabelecido na constituição provisória de 1944. De fato, mantendo um presidente eleito popularmente com potencialmente significativos poderes, o projeto de lei visa mudar o modelo de governança islandesa de 1944 na direção "Parlamentarismo restrito", de acordo com a prática constitucional do Canadá, Alemanha, Índia, Itália, Japão, África do Sul e muitas outras nações. ${ }^{?}$

\subsection{PROCESSO CONSTITUINTE ISLANDÊS}

A constituinte da Islândia foi composta por 25 membros, cuja maioria dos debates foram discutidas as questões levantadas pelos internautas.

O trabalho foi feito em três rodadas sobrepostas. Primeiro, a cada semana, o Conselho Constitucional publicou em seu site alguns novos artigos provisórios para leitura pelo público. Em geral, duas a três semanas depois de receber comentários e sugestões do público, bem como de especialistas, o Conselho publicou versões revisadas desses artigos no site. Então, em uma rodada final, propostas para mudanças no documento como um todo foram debatidas e votadas em artigo por artigo, e a versão final do projeto de lei foi preparada. No final da última rodada, cada artigo foi aprovado por uma esmagadora maioria de votos. A passagem dos artigos

\footnotetext{
${ }^{7}$ GYLFASON, Thorvaldur. From colapse to Constittution: the case of Iceland. Traduzido pelo presente autor. 1. ed. Reykjavík. GlobalGovernanceandEconomicDynamism. p. 19-20.
} 
sobre o sistema eleitoral parlamentar e sobre os recursos naturais foi seguida de aplausos espontâneos. ${ }^{8}$

\subsection{DO LEGADO DO CROWDSOURCED PARA O MUNDO}

Todo o processo constituinte ocorrido na Islândia servirá como exemplo para as outras nações no que tange a elaboração de normas, pois um país pequeno referente à extensão territorial conseguiu inovar veementemente $\mathrm{o}$ conceito de Democracia direta trazendo-o à contemporaneidade.

Dito isto, Mesmo na Europa Oriental e Central, que viu cerca de 25 novos constituições surgiram após 1990, os comunistas - claramente responsáveis pelo colapso de seus países e, principalmente, admitindo o mesmo, até o ponto de desculpando-se por sua má gestão, ou pior contribuiu para a elaboração da constituição esforços de seus concidadãos ao invés de tentar sabotá-los. Seus sucessores queriam incluir os comunistas no processo e, na maioria dos lugares, eles aceitaram. Prontidão semelhante cooperar não foi iminente dos dois partidos políticos que governavam a Islândia de 1995 a 2007, privatizando os bancos à la russe e, assim, preparando o terreno para desaparecer alguns anos depois. Em vez disso, declararam desde o início que não queriam participar no projeto, dando as costas à posição oficial dos líderes anteriores de seus partidos que prometeram repetidamente revisar a constituição, e não o fizeram repetidamente.

Compreensivelmente, com essa falta de cooperação de dois dos cinco partidos políticos representado no parlamento, não podemos esperar que o restante de nós conceda a eles o direito de veto.

Em vez disso, devemos dizer a eles: todos estavam livres para concorrer à Assembléia Constitucional, você teve as mesmas oportunidades que todos os demais para oferecer seus serviços a cada passo do caminho, e agora o projeto está pronto, tendo sido aprovado por unanimidade pelo Conselho Constitucional, então só temos mais uma coisa a fazer para terminar o trabalho e permitir que as pessoas decidir em um referendo nacional onde cada voto tem o mesmo peso. Os oponentes precisam lembrar como a constituição americana foi aprovada em 1787-

\footnotetext{
${ }^{8}$ GYLFASON, Thorvaldur. From colapse to Constittution: the case of Iceland. Traduzido pelo presente autor. 1. ed. Reykjavík. GlobalGovernanceandEconomicDynamism. p. 459.
} 
88: por 89 a 79 votos em Virginia, 30 a 27 em Nova York, 187 a 168 em Massachusetts, e assim por diante (Maier, 2010). No Rhode Island, o único estado a realizar um referendo popular, foi rejeitado. Mas as regras do o jogo estipulava que a aprovação por maioria simples dos representantes eleitos em pelo menos nove estados de 13 seriam suficientes, e isso seria. Diante de tal perspectiva, o islandês para ser justo, um ou dois parlamentos. ${ }^{9}$

\title{
3 DOS DIFERENTES TIPOS DE DEMOCRACIA
}

\subsection{DEFINIÇÃO DE DEMOCRACIA}

\begin{abstract}
Democracia é um conceito histórico. Não sendo por si um valorfim, mas um meio e instrumento de realização de valores essenciais de convivência humana, que se traduzem basicamente nos direitos fundamentais do homem. Compreende-se que a historicidade desses a envolva na mesma medida, enriquecendo lhe o conteúdo a cada etapa do envolver social, mantido sempre o princípio básico de que ela revela um regime político em que o poder repousa na vontade do povo. Sob esse aspecto, a democracia não é um mero conceito político abstrato e estático, mas é um processo de afirmação do povo e de garantia dos direitos fundamentais que o povo vai conquistando no correr da história. Nesse processo vai-se configurando também a noção histórica de povo. A concepção de povo tem variado com o tempo. Por isso é que a democracia da antiguidade grega não é a mesma dos tempos modernos; nem a democracia burguesa capitalista corresponde à democracia popular. $^{10}$
\end{abstract}

Não se deve, como costumavam fazer certas pessoas, definir simplesmente a democracia como o governo em que a maioria domina, nas próprias oligarquias e em qualquer outra parte, é sempre a maioria que se sobressai. Nem tampouco a oligarquia é o regime da minoria.

Seja um povo composto de mil e trezentas pessoas ao todo; dentre estas mil e trezentas pessoas, suponhamos mil ricas que excluem do governo os trezentos pobres, embora livres e semelhantes a elas qualquer outro respeito; ninguém dirá que isso é uma democracia.

\footnotetext{
${ }^{9}$ GYLFASON, Thorvaldur. From colapse to Constittution: the case of Iceland. Traduzido pelo presente autor. $1^{\circ}$ ed. Reykjavík. GlobalGovernanceandEconomicDynamism. p. 38-42.

${ }^{10}$ SILVA. José Afonso da. Curso de Direito Constitucional Positivo. 40. ed. São Paulo: Malheiros, 2015, p. 114.
} 


\begin{abstract}
Da mesma forma, se os pobres, embora em menor número, forem mais poderosos do que os ricos, ninguém chamará isso de oligarquia. Nenhuma outra cidade tampouco o seria, se os ricos não fossem admitidos nos cargos. Portanto, deve-se antes chamar democracia o Estado que os homens livres governam, e oligarquia o que os ricos governam. O acidente faz com o número seja maior ou menor, sendo o comum que o maior número seja o dos homens livres e o menor, o dos ricos. ${ }^{11}$
\end{abstract}

Portanto, a democracia, independente do número de pessoas que estão para decidir, traz consigo o espírito de inclusão, em que os homens têm o direito de opinião, não somente determinada classe da sociedade quem tem o privilégio de escolha, situação esta que se remete à oligarquia, a qual vai de encontro com o princípio democrático.

\title{
3.2 DEMOCRACIA DIRETA
}

O termo democracia, como é sabido, teve a certidão de nascimento na Grécia, como o regime que se aplica. Segundo Forrest e Ehrenberg, teria surgido numa data imprecisa do segundo quartel $\mathrm{V}$ a.C. além de dêmos, entra na sua formação, como segundo elemento de composição, Krat de Kratos (que significa força ou soberania). Trata-se de um composto do mesmo tipo de aristocracia-regime que se dominam os aristoi, os melhores no sentido social e de plutocracia sistema político em que o acesso ao poder se baseia na riqueza. Democracia é assim o governo pelo dêmos, o povo. Mas que era o dêmos no apogeu da democracia ateniense, no século V?

Um passo dos memoráveis de Xeno procura definir o seu conteúdo social para o comum das pessoas. Sócrates dialoga com Eutidemo e pergunta-lhe se considera possível saber o que é a democracia sem ter a noção do que é o dêmos. O interlocutor responde negativamente e, ao ser interrogado sobre o sentido que atribui a tal termo, responde que são pobres, dentre os cidadãos. Elucidativa, esta definição demonstra com toda evidência que, no pensar comum, os pobres constituem a base e a força de tal regime; deixa perceber, por outro lado, uma oposição surda e certos laivos de desprezo por esse povo. Ora o conflito entre os dêmos e os plousioi constitui uma das características que marcam a história da democracia.

${ }^{11}$ ARISTÓTELES. A Política. 2. ed. São Paulo: Marins s, 1998. p 119-126, 85-125. 
Ao falar de democracia grega, pensamos de modo geral no regime ateniense, se bem que em outros Estados o povo tenha atingido o poder, em alguns possivelmente até o primeiro do que em Atenas, como aconteceu em Mileto, Mágara, Samos, Quios onde é provável terem existido instituições democráticas desde inícios ou meados do século VI a. C. Atenasé, no entanto a mais conhecida, a que nos fornece mais s e dados para o estudo, a que levou o regime a maior perfeição, a que nos legou princípios ainda hoje fundamentais. Atenas, além disso, inspirou muitos outros Estados gregos a seguir o seu exemplo. À sua volta formouse uma simaquia de Delos, ou Primeira Confederação Ateniense, como também lhe chamam, que esteve na base de um império. Adoptaram de modo geral o regime democrático. Esta simaquia, no século $\mathrm{V}$ a. $\mathrm{C}$., formava um bloco que se opunha a um liderado por Esparta, a Simaquia do Peloponeso, em cujos Estados dominava a oligarquia.

Foi, portanto, a consciência do povo que, após a queda da tirania em 510 a. C., permitiu evitar a reação aristocrática ainda tentada por Iságoras e o apoiou para proceder a uma reforma completa da constituição de que Heródoto e Aristóteles apontam em linhas gerais, embora atribuíam às reformas objetivos diferentes.

O passo decisivo tinha sido dado e, a partir de então, já se pode falar verdadeiramente em democracia, regime que de início não teria, contudo, esse nome. É possível que a revolução política que começa com a expulsão dos Hípias e culmina com a reforma de Clístenes tenha sida designada pela palavra isonomia e que esta constituísse uma ideia/força utilizada na luta política, em palavras de ordem e mesmo de mesa. Características mais destacada da democracia grega, em especial da de Atenas, a noção de isonomia deve ter surgido, se não antes, pelo menos nos inícios do século V a. C., já que parecem ter sido divulgadas por essa época as canções de mesa respeitantes aos Tiranicidas, nas quais são exaltados Harmódi e Aristogiton, por terem tornado Atenas isonômica, com o assassinato de Híparco, um dos tiranos.

Aplicado à democracia segundo Aristóteles por Sólon, mas mais provavelmente porclístenes, o princípio tem um sentido diferente: procurava, por um lado, limitar a luta e as manobras a que toda eleição se presta e, por outro, impedir o desenvolvimento de grandes autoridades individuais. Neste aspecto a tiragem à sorte conjuga-se com a proibição de escolha do mesmo cidadão, em anos seguidos, para os mesmos cargo sou órgãos. Assim se anulava a extensa e equitativa soberania popular. Todos, fossem eles ricos ou pobres, cultos ou menos cultos, se encontravam em 
igualdade de condições. Em vez de funcionários de carreira, eram os próprios cidadãos que geriam o Estado.

A democracia criou, no entanto um conjunto de medidas e mecanismos que lhe permitissem manter o princípio da tiragem à sorte que considerava essencial, mas lhe minorassem os riscos daí derivados: a colegialidade que atenuava a gravidade de um possível erro e precavia contra a incompetência ou pior qualificação de alguns elementos; a sujeição dos futuros magistrados a juramento e à verificação, antes da posse, dos seus títulos e comportamento cívico; não aplicação da tiragem à sorte em campos- como é o caso dos cargos militares ou financeiros, em que a colegialidade não era possível ou nem que uma determinada qualificação era requerida.

A população total de Atenas possuía em torno de trezentos mil habitantes. Desses apenas cerca de trinta a quarenta mil seriam cidadãos. Como apenas os cidadãos tinhas direitos políticos, esse povo seria afinal somente de cerca de dez a quinze por cento da totalidade da população. Daí que pareça justificar-se a afirmação de Ehering de que a democracia ateniense não passava de uma aristocracia alargada ou a recusa de $\mathrm{K}$. Reinhardt em ver qualquer parentesco entre as antigas e as modernas democracias. Atenas, como polis que era e como já vimos, tinha um sistema direto e plebiscitário, o que condicionava o número dos cidadãos. No entanto, apesar dessa condicionante, além de estender a cidadania até onde lhe foi possível, deu peso político efetivo aos mais pobres. ${ }^{12}$

Nota-se que essa peculiaridade na polis de Atenas na Grécia antiga deu um determinado desdobramento histórico para que a democracia fosse ganhando determinada característica de acordo com a conjuntara histórica que se encontrasse, mas mesmo assim a democracia que até então existia na referida pólis, não deixara de ser seleta, pois só determinado grupo social tinha voz ativa nas decisões.

Nesta senda, não obstante as críticas existentes pelo historiador (José Ribeiro Ferreira) ao modelo de democracia na Pólis Atenas, não deixou de ser o pontapé inicial para a desenvoltura de uma democracia participativa.

${ }^{12}$ FERREIRA, José Ribeiro. A Grécia Antiga Sociedade e Política. 18. ed. Rio de Janeiro: Edições 70, 1992. 


\subsection{DEMOCRACIA INDIRETA}

O douto Professor José Afonso da Silva traz a melhor definição para esse desdobramento, e também bastante didática para o leitor; "Democracia indireta", chamada democracia representativa, é aquela na qual o povo, primária do poder, não podendo dirigir os negócios do Estado diretamente, em face da extensão territorial, da densidade demográfica e da complexidade dos problemas sociais, outorga as funções de governo aos seus representardes, que elege periodicamente.

\subsection{DEMOCRACIA PARTICIPATIVA}

$\mathrm{O}$ que se quis acentuar com as considerações supra é que o sistema de partidos, como sufrágio universal e a representação proporcional, dá à democracia representativa um sentido mais concreto, no qual desponta com mais nitidez a ideia de participação, não tanto a individualista e isolada do eleitor no só momento de eleição, mas a coletiva organizada. Mas será ainda participação representativa, que assenta no princípio eleitoral. Ora, qualquer forma de participação que dependa de eleição não realiza a democracia participativa no sentido atual dessa expressão. A eleição consubstancia o princípio representativo, segundo o qual o eleito pratica atos em nome do povo.

O princípio participativo caracteriza-se pela participação direta e pessoal da cidadania na formação dos atos de governo.

As primeiras manifestações de democracia participativa consistiram nos institutos de democracia semidireta, que combinam instituições de participação direta com instituições de participação indireta, tais como:

A iniciativa popular pela qual se admite que o povo apresente projetos de lei ao legislativo, desde que subscritos por número razoável de eleitores, acolhida no art. 14, III, e regulada no art. 61, parágrafo $2^{\circ}$; o projeto precisa ser subscrito por, no mínimo, um por cento do eleitorado nacional (cerca de 800.000 eleitores), distribuídos pelo menos em cinco Estados, com não menos de três décimos por cento dos eleitores de cada um dele; estatui-se também que lei disporá sobre a iniciativa popular no processo legislativo estadual, enquanto que, em relação aos Municípios, já se dispôs que a sua lei orgânica adotará a iniciativa popular de leis de interesse especifico do Município, da cidade ou de bairros, através de manifestação de, pelo menos, cinco por cento do eleitorado; pena, 
não ter sido acolhida a iniciativa popular em matéria constitucional; $\mathrm{O}$ referendo popular que se caracteriza no fato de que projetos de lei aprovados pelo legislativo devam ser submetidos à vontade popular, atendidas certas exigências, tais como pedido de certo número de eleitores, de certo número de parlamentares ou do próprio chefe do executivo, de sorte que o projeto se terá por aprovado apenas se receber votação favorável do corpo eleitoral, do contrário, reptar-se-á rejeitado.

"A constituição adotou outras formas de democracia participativa, como as consagradas nos arts. 10, 11, 31, parágrafo $3^{\circ}, 37$, parágrafo $3^{\circ}, 74$ parágrafo $2^{\circ}, 194$, VII, 206, VI, 216, parágrafo $1^{\circ} ., 13$

\section{DA RELAÇÃO DO CROWDSOURCED COM A OBRA "A DEMOCRACIA NA AMÉRICA"}

\subsection{ONE MAN, ONE VOTE}

No presente capítulo serão abordados aspectos escritos pelo autor Alexis de Tocqueville, referente aos degraus que povo americano subiu até se chegar na glamorosa democracia, o que consolidou para cada homem o direto a ter um voto.

Importante relembrar que nessa parte do trabalho, tem como escopo a história dos Estados Unidos, pois a democracia conquistada naquele país foi um grande marco para as grades civilizações, pois tal conquista serviu como parâmetros para construção de democracias em outros país, até mesmo no Brasil.

\subsection{SOBERANIA AMERICANA}

Alexis de Tocquiville discorre de modo claro sobre os princípios da soberania do povo na américa, os quais serão abortados no presente tópico;

\footnotetext{
${ }^{13}$ SILVA. José Afonso da. Curso de Direito Constitucional Positivo. 40. ed. São Paulo: Malheiros, 2015, p. 143-145.
} 
Na América, o princípio da soberania do povo não é oculto ou estéril, como em certas nações; ele é reconhecido pelos costumes, proclamando pelas leis; estende-se com liberdade e chega sem obstáculos às últimas consequências.

Se há um país no mundo em que se possa esperar apreciar por seu justo valor o dogma da soberania do povo, estudá-lo em sua aplicação aos assuntos da sociedade e julgar suas vantagens e seus perigos, esse país é seguramente a América.

A sociedade americana de então ainda não estava preparada para adotá-lo em todas suas consequências. As luzes na Nova Inglaterra, as riquezas ao sul do Hudson exerceram por muito tempo, como foi mostrado no capítulo anterior, uma espécie de influência aristocrática que tendia a concentrar em poucas mãos os exercícios dos poderes sociais. Ainda estava longe o dia em que todos os funcionários públicos seriam eleitos e todos os cidadãos, eleitores. O direito eleitoral estava em toda a parte contido em certos limites e subordinando à existência e um censo. Esse censo era muito fraco no Norte, mas considerável no sul.

A revolução americana estourou. O dogma da soberania do povo saiu da comuna e apoderou-se do governo; todas as classes se comprometeram por sua causa; combateu-se e trinfou-se em seu nome, ele se tornou a lei das leis. ${ }^{14}$

\section{Por fim, Tocquiville encerra a deliberação no que tange a soberania, o mesmo realça a forma da atuação do povo americano na composição das leis, de quem participa no legislativo e a participação nas eleições para a escolha do homem que irá comandar o executivo;}

Outros há em que a força é dividida, situando-se ao mesmo tempo na sociedade e fora dela. Nada parecido se vê nos Estados Unidos; lá a sociedade age por si e sobre si mesma. Só há força em seu seio; quase não se encontra ninguém que ouse conceber e, sobretudo, exprimir a ideia de buscá-la em outra parte. O povo participa da composição das leis pela escolha dos legisladores, da sua aplicação pela eleição dos agentes do poder executivo; podemos dizer que governa por si mesmo, a tal ponto a importância deixada à administração é fraca e restrita, a tal ponto ela é marcada por sua origem popular e obedece ao poder de que emana.

O povo reina sobre o mundo político americano como Deus sobre universo. Ele é causa e o fim de todas as coisas, tudo provém dele e tudo nele se absorve. ${ }^{15}$

Tem-se, portanto, que a forma de que o aludido povo elabora suas normas é, sem sombra de dúvidas, um dos meios eficientes para consulta popular e uma inovação no século XVIII que posteriormente serviu de base para outras noções usar este mesmo modelo.

${ }^{14}$ DE TOCQUIVILlE, Alexis. Da Democracia na América. 2. ed. São Paulo: Martins s, 2005, p. 65-66.

${ }^{15}$ Ibidem, p. 68 . 


\title{
4.3 CONSTITUIÇÃO FEDERAL DOS ESTADOS UNIDOS
}

\author{
Alexis de Tocquiville com maestria faz bons apontamentos sobre \\ a carta política americana, paralelo a isso o aludido autor faz um apanhado \\ histórico da constituição americana;
}

Considerei até aqui cada Estado como um todo completo e mostrei os diferentes mecanismos que o povo aciona neles, assim como os meios de ação de que se vale. Mas todos esses Estados que encarei como independentes são forçados a obedecer, em certos casos, a uma autoridade superior, que é a da União. Chegou a hora de examinar a parte de soberania que foi concedida à União e dar uma rápida olhada na constituição federal.

As treze colônias que sacudiram simultaneamente o jugo da Inglaterra no fim do século passado tinham, como já disse, a mesma religião, a mesma língua, os mesmos costumes, quase as mesmas leis; eles lutavam contra um inimigo comum, logo deviam ter fortes motivos para se unirem intimamente umas às outras e se absorvem numa só e mesma nação.

Mas cada uma delas, tendo sempre levado uma existência à parte e um governo a seu alcance, criara interesses assim como usos particulares e rejeitava uma união sólida e completa que fizesse desaparecer sua importância individual numa importância comum. Daí duas tendências opostas: uma que levava os anglo-americanos a se unirem, a outra que os levava a se dividirem.

Enquanto durou a guerra com a mãe-pátria, a necessidade fez prevalecer $\mathrm{o}$ princípio da união. $\mathrm{E}$ conquanto as leis que constituíam essa união fossem defeituosas, o vínculo comum subsistiu a despeito delas.

Mas assim que a paz foi firmada, os vícios da legislação mostraramse a descoberto: o Estado pareceu dissolver-se de repente. Cada colônia, tornando-se república independente, apoderou-se da soberania inteira. O governo federal, que sua própria constituição condenava à fraqueza e que o sentimento do perigo público já não sustentava, viu seu pavilhão abandonado aos ultrajes dos grandes povos da Europa, enquanto não podia encontrar recursos suficientes para enfrentar as nações indígenas e pagar juros das dívidas contraídas durante a guerra da Independência. A ponto de perecer, declarou ele próprio oficialmente sua impotência e apelou para o poder constituinte. ${ }^{16}$

Conclui-se que até o momento em que se concretizou a União dos Estados Unidos foi um procedimento que levou certo desgaste de negociações perante os lideres dos Estados, pois à medida que foi se dando certas autonomias aos respectivos entes, mais eles queria se tornar uma republica independente, mas com o afinco dos que estiveram à frente das

${ }^{16}$ De Tocquiville, Alexis. Da Democracia na América. 2. ed. São Paulo: Martins s, 2005, p.127129. 
negociações foi possível à criação de um Estado que abarcasse todos os outros federados e uma constituição sólida que perdura até os dias de hoje.

\subsection{CONSIDERAÇÕES FINAIS DA OBRA "A DEMOCRACIA NA AMÉRICA"}

Nota-se por tudo o que foi explanado, que o povo americano lutou pela liberdade política em face da corte inglesa, um povo massacrado pelos altos tributos cobrados pela aludida corte, com isso fez surgir no americano o sentimento patriota, o qual vigora até os dias de hoje. E esse mesmo povo que se rebelou contra o país em que colonizava as treze colônias, lutou para a institucionalização da democracia.

Com a chegada da suprema lei americana em 1787, a democracia chegou no Novo Mundo, assim se consagrou o objetivo da luta dos Americanos, e que por sua vez todos os Estados que compõe os EUA, adotou o sistema político supramencionado. E assim sendo se concretizou o famoso One man, one vote.

\section{DO CABIMENTO DO CROWDSOURCED NO BRASIL}

\subsection{LEGITIMIDADE DOS USUÁRIOS PARA DECIDIR}

Nota-se que a ferramenta, Internet, a comunicação se tornou algo simples, pois a troca de informação em grandes distâncias num curto lapso de tempo é algo banal no convívio social.

Posto que, no Brasil um país mastodôntico, em número de população quanto em extensão territorial, à aludida ferramenta foi promissor para facilitação da comunicação.

O IBGE em suas pesquisas de praxe confirmou que 69,9 da população brasileira estão conectadas na Internet $^{17}$, portanto mais da metade dos brasileiros tem o privilégio de se comunicarem, sem se tornar oneroso para os mesmos.

\footnotetext{
${ }^{17}$ IBGE. Diretoria de pesquisas. Coordenação de trabalho e rendimento. Pesquisa Nacional por amostras de domicílios contínuas 2016/2017.
} 
Diante da abordagem inicial, imprescindível dizer que a Internet não pode ser encarada somente como meio de comunicação, a mesma pode ser eficaz, na mesma medida, como artificio de consulta à população, como por exemplo, a realização de plebiscitos e referendos.

O dado trazido na pesquisa mencionada, feita pelo IBGE, respalda a legitimidade que se daria ao ato de consulta ao povo, pois com mais da maioria da população tendo acesso à Internet, qualquer decisão tomada pelos usuários, jamais poderá ser considerada ilegítima.

Nesta senda, além de ser mais uma forma de democracia participativa, também é um artificio que não irá trazer muitos dispêndios ao Estado, uma vez que a realização de eleições não é barata (a título de curiosidade no primeiro turno das eleições de 2018 foram gastos aproximadamente $\mathrm{R} \$ 700.000 .000,00$ (setecentos milhões de reais somente com mesários ${ }^{18}$ ).

Temas polêmicos, como por exemplo, a descriminalização da venda de maconha, aborto e etc., não são decididos muito das vezes por questões que não merecem ser discutido no presente trabalho. Então com o "plebiscito virtual" tais temas poderão ser decididos de forma soberana pelos internautas, legítima e com um custo bem menor equiparado à onerosidade das eleições realiza no Brasil.

Indubitavelmente a realização de consultas periódicas aos que estão conectados à Internet, não mitiga em hipótese alguma o primado da democracia, pois esse procedimento permite ampla liberdade para as decisões dos mesmos.

Por fim, os meios tecnológicos estão cada vez mais avançados e dando aos povos ergonomia no trabalho, no lazer, vida social, etc., mas porque não se poderia dar o mesmo benefício à Política? Conclui-se inequivocamente que, a Internet é o meio possível de se ter uma possível democracia direta no Brasil de forma eficaz.

\subsection{MEIOS DE UNIFORMIZAÇÃO E SEGURANÇA NAS DECISÕES VIRTUAIS}

O Tribunal Superior Eleitoral órgão responsável pela realização e fiscalização das eleições no Brasil. Nesse sentido a realização do "plebiscito virtual", deverá ser regulamentado pelo aludido tribunal, pois 
mesmo tem a atribuição constitucional de uniformizar o acesso à todos os eleitores, não havendo descriminalização com aqueles que não tem acesso à Internet, assim sendo a atitude do TSE estará de acordo com os ditames

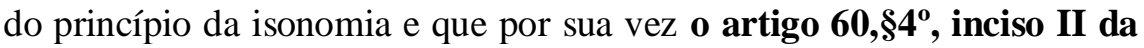
Carta Política, que é uma das cláusulas pétreas do ordenamento jurídico brasileiro, será cumprido à risca.

Nesse ponto, a contabilização dos votos irá ser mais dinâmica, pois todas as zonas eleitorais estarão interligas em um único sistema, por consequência o número de funcionários irá diminuir, pois a transferência dos dados da urna eletrônica para o sistema do TSE não vai ser preciso, porque os usuários votarão diretamente no sistema do Tribunal Superior Eleitoral.

No tocante, a segurança de dados e individualização do usuário/eleitor a ICP-Brasil (Instituto Nacional de Tecnologia da Informação), que é um órgão do poder executivo nacional responsável por chaves públicas e missão de certificados, irá dar segurança ao inovador procedimento democrático, como forma de inibir a atuação de hackers, assim sendo não se poderá cogitar a máxima de que o crowdsourced tem margem de ser fraudulento tanto quanto antigo modo de consultar a soberania popular.

Por fim, nota-se que atuação conjunta do TSE e do ICP-Brasil, vai ao encontro dos interesses dos brasileiros, pois o primeiro garantirá que todos poderão participar do mencionado plebiscito virtual e o segundo vai permitir segurança, para que o novo processo democrático não seja maculado.

\subsection{CELERIDADE NA APURAÇÃO DOS VOTOS}

A uniformização do sistema eleitoral vai permitir de forma segura a rapidez em se divulgar o resultado do pleito, pois com o software integrado não haverá mais necessidade de ter o dispendioso trabalho de se tirar a urna eletrônica e leva-la ao cartório eleitoral e, posteriormente, ser os dados encaminhado ao TRE do respectivo estado e, por fim somente, que os dados vão chegar ao TSE.

Depreende-se que a Crowdsourced vai permitir amplo acesso da população brasileira nas mais variadas discussões que estão em xeque no panorama politico brasileiro e, com a celeridade no sistema eleitoral 
integrado, tais problemas vão ser democratizados com a suas resoluções num curto lapso temporal.

A titulo de exemplo em relação dinâmica de apuração dos votos, é a complexidade de translado das urnas eletrônicas no Estado do Amazonas, uma vez a Crowdsoruced aplicada no Brasil, não haverá altos custo para tal e muito menos o aludido problema.

Por fim, não qualquer óbice para implantação do Crowdsoruced no Brasil, o país só terá ganhos com essa moderna forma de consulta da população.

\section{CONSIDERAÇÕES FINAIS}

O presente artigo teve como objetivo de trazer à baila do mundo jurídico, a nova forma de exercício da democracia pela sociedade.

A evolução dos meios tecnológicos deve sim influenciar na política, pois método atual de consulta à população está ultrapassado, com isso, inovar o processo decisório, é a medida mais sensata para decidir os temas polêmicos atuais.

O trabalho destrinchou ponto a ponto a respeito da democracia, o quanto ela é um sistema político de suma importância aos povos e jamais poderá ser substituída. Por outro lado, a aquela tem que acompanhar as mutações da sociedade. Junto a isto, a existência do crowdsourced é a prova cabal de que é imperativo a sua inserção no meio democrático, sob pena de inutilizá-la.

Enfim, a participação colaborativa da população, no tocante a decisão de variados temas que estão em xeque, é de suma importância no desenvolver da história da humanidade. E a inovação que o crowdsourced irá trazer para a comunidade política, facilitará com que aquela história seja contada com maior facilidade, sem discriminação, segura e claro democrática.

\section{REFERÊNCIAS}

ARISTÓTELES. A política. São Paulo: Martins s, 1998.

DE TOCQUIVILle, Alexis. Da Democracia na América. São Paulo: Martins s, 2005. 


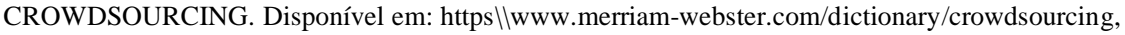
acessado em 14 set. 2018.

FERREIRA. José Ribeiro. A Grécia Antiga Sociedade e Política. Rio de Janeiro: Edições, 1992.

GYLFASON, Thoryvaldur. From Collapse to Constitution: the case of Iceland. Reyjevic Global Govermaneced and Economic Dynamin, 2012.

IBGE. Plataforma de pesquisas. Coordenação de trabalho e rendimento. Pesquisa Nacional por Amostras contínuas, 2016/2017.

LENZA, Pedro. Direito Constitucional. São Paulo: Saraiva, 2017.

SILVA, José Afonso Da. Curso de Direito Constitucional Positivo. São Paulo: Malheiros, 2015.

MICHAELIS, Henriette. Dicionário Michaelis em Inglês. 22a ed. São Paulo. Melhoramentos.2015 